\title{
Research Progress of Impurity Removal from Metallurgical Slag and Strengthening Metallurgical Process by External Electric Field
}

\author{
Wang Haichuan ${ }^{1,2, ~ *, ~ L i a o ~ Z h i y o u ~}{ }^{1,2}$, Wang Bowen ${ }^{1}$, Wu Ting ${ }^{1,2}$, Lv Ningning ${ }^{1,2}$, Deng Aijun ${ }^{1}$, \\ Wu Liushun ${ }^{1,2}$ \\ ${ }^{1}$ School of Metallurgical Engineering, Anhui University of Technology, Ma'anshan, China \\ ${ }^{2}$ Key Laboratory of Metallurgical Emission Reduction \& Resource Recycling (Ministry of Education), Anhui University of Technology, \\ Ma'anshan, China
}

\section{Email address: \\ which@ahut.edu.cn (Wang Haichuan) \\ *Corresponding author}

\section{To cite this article:}

Wang Haichuan, Liao Zhiyou, Wang Bowen, Wu Ting, Lv Ningning, Deng Aijun, Wu Liushun. Research Progress of Impurity Removal from Metallurgical Slag and Strengthening Metallurgical Process by External Electric Field. Journal of Energy and Natural Resources.

Vol. 10, No. 2, 2021, pp. 39-45. doi: 10.11648/j.jenr.20211002.11

Received: February 15, 2021; Accepted: April 9, 2021; Published: April 16, 2021

\begin{abstract}
Based on the demand of the development of circular economy, the utilization of metallurgical solid waste has attracted more and more attention, one of the main ways of comprehensive utilization of metallurgical slag is internal recycling in steel plant to replace limestone as smelting flux, so it need to removal of phosphorus and sulfur from molten slag to decrease the burden of dephosphorization and desulfurization in the steelmaking process. In this paper, the current recycling situation of phosphorus-containing steel slag and sulfur-containing waste refining slag is briefly summarized, these relevant researches show that, the methods of dephosphorization of steel slag include reduction method (such as carbon reduction method or silicon reduction method) and gasification method, the dephosphorization ratio with reduction method reached $95.5 \%$, and the greatest dephosphorization rate with gasification method can reach $81.23 \%$, these treatment methods need a long time and treatment temperature is too high. Two main methods to remove sulfur from refining slag, oxidation method and hydrothermal method, oxidative roasting desulfurization and the sulfur removal rate was about $95 \%$. And the latest research progress of using electric field to strengthen slag-metal reaction and component migration in metallurgical melt is also summarized. Electric field treatment of metallurgical melts can affect the physicochemical properties, such as viscosity, solidification structure, grain refinement, material properties, partition coefficient of component and the activity of solute, etc. It can enhances mass transfer reaction in metallurgical process and make oxygen transfer between molten iron and molten copper increase $2 \sim 3$ times. It also can enhanced the migration ability of components between molten slag and metal, it is a great significance for electric field strengthening slag desulfurization because of enough sulfur ions in slag. There is a non-equilibrium phosphorus capacity different from conventional thermodynamic properties under the action of electric field, the lower non-equilibrium phosphorus capacity improves the phosphorus removal efficiency of phosphorus-containing steel slag.
\end{abstract}

Keywords: Metallurgical Melt, Component Migration, Slag-Metal Reaction, Electric Field

\section{Research Significance and Purpose}

Circular economy is based on the principle of "reduction, recycling and reuse", and adheres to the ecological civilization thought of "Lucid waters and lush mountains are invaluable assets." Its purpose is to achieve the most effective use of resources, reduce environmental load, and promote the coordinated and sustainable development of social, economic and environmental benefits. Metallurgical production is not only a major consumer of resources and energy, but also a major producer of metallurgical solid waste which is also called metallurgical secondary resources. Therefore, green metallurgy including the utilization of metallurgical solid waste resources is the development direction of circular economy. 
It is estimated that over 2 billion tons of crude steel are produced every year in the world, and the amount of metallurgical secondary resources is about 600 700 million tons of blast furnace slag, 200 300 million tons of steel slag and 20 million tons of waste refining slag. Because blast furnace slag is simple in composition, stable in performance and easy to use, while steel slag and waste refining slag affect resource recycling due to their unstable composition, performance and impurity elements.

Two kinds of slag are produced in steelmaking process, namely converter steel slag and waste refining slag. Steel slag is one of the by-products of steelmaking process, and its yield is about $10 \% \sim 15 \%$ of crude steel output, and waste refining slag is also the by-product of secondary refining of molten steel. These two kinds of slag can't be recycled cleanly and effectively because of the impurity phosphorus in steel slag and sulfur in waste refining slag. Now the utilization rate of steel slag is only about $30 \%$, the key problem is to remove the impurity element phosphorus or sulfur in slag, Promoting slag-metal reaction, strengthening metallurgical process, improving metallurgical effect, removing impurity elements (mainly $\mathrm{P}$ and $\mathrm{S}$ ) and inclusions are important research topics in the field of metallurgy. At present, most of the research focused on the theory and technology of slag-metal reaction, such as properties of $\mathrm{CaO}-\mathrm{Al}_{2} \mathrm{O}_{3}-\mathrm{SiO}_{2}$ based slag system [1] and numerical simulation of metallurgical physicochemical process [2] etc.

Metallurgical reaction in high temperature is mostly liquid-liquid two-phase reaction between metal and slag. Molten slag is conductive melt with ionic structure, which is characterized by oxidation reduction reaction of electron transfer between two phases, belonging to electrochemical control mechanism [3]. The electric field is applied to the metallurgical process to strengthen the electron transfer between molten metal and slag, it can promote the oxidation-reduction process and greatly improve the metallurgical efficiency. At the same time, the thermal effect produced by the electric field can be used to compensate the

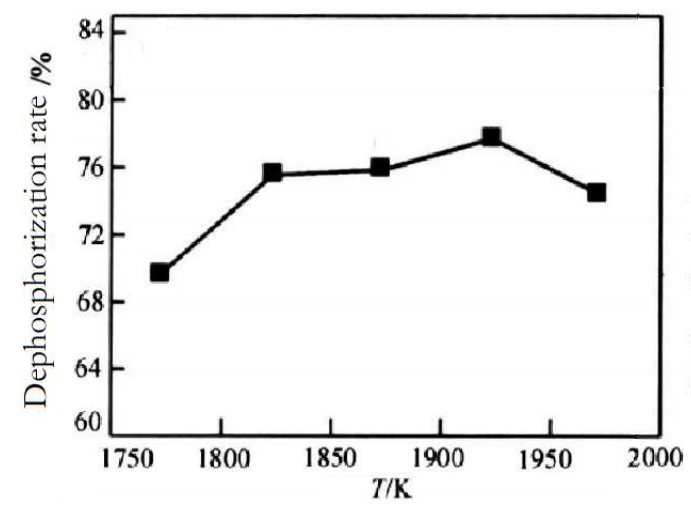

Figure 1. Effect of temperature and nitrogen flow rate on dephosphorization rate [8].

\subsection{Research on Removal of Phosphorus from Steel Slag}

The methods of dephosphorization of steel slag include carbon or silicon reduction. Miyashita Masao et al. [5] studied that carbon and fluorite were added to the slag and oxygen was blown after converter tapping, $90 \%$ of $\left(\mathrm{P}_{2} \mathrm{O}_{5}\right)$ in slag could be

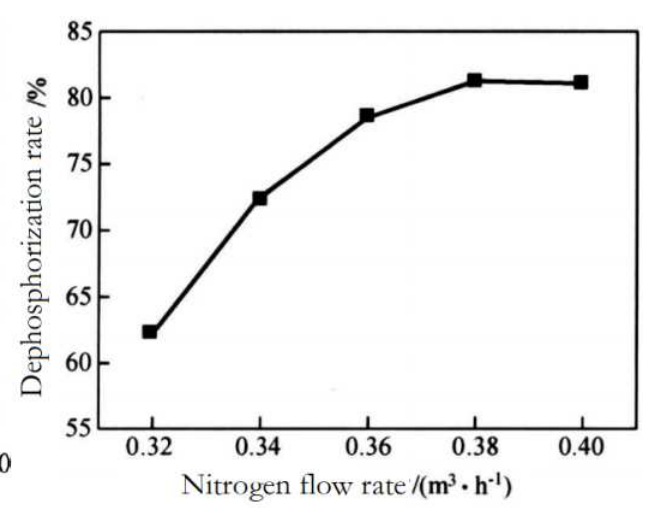

heat of the treated slag. Therefore, for phosphorus-containing steel slag or sulfur-containing waste refining slag, low phosphorus (or sulfur) slag and phosphorus (or sulfur)-containing alloy can be obtained after phosphorus (or sulfur) removal, which can get a double advantage. As a special outfield, electric field has been applied in metallurgy, especially in processing metal melt and grain refinement. In order to improve the separation of impurity elements and the utilization efficiency of resources, the electrochemical reaction between slag and metal and the migration mechanism of impurity elements were studied by using electric field to strengthen the electrochemical reaction between slag and metal in metallurgical process.

\section{Research on Removal of Phosphorus and Sulfur from Molten Slag}

With the increasing environmental protection requirements of enterprises, one of the main ways of comprehensive utilization of metallurgical slag is the internal circulation of the plant to replace limestone as smelting flux, It is impossible to avoid the influence of phosphorus and sulfur in the slag on the quality of molten steel, and increase the burden of dephosphorization and desulfurization in the steelmaking process. Therefore, the harmful elements phosphorus and sulfur have become the main factors limiting their recycling. To solve this problem, the first thing is to remove the phosphorus in steel slag or sulfur in waste refining slag. But $\mathrm{P}$ in high phosphorus steel slag exists in the form of apatite or phosphate, which leads to the lack of practical and effective way for the utilization of steel slag. Similarly, after the desulfurization task of refining slag in ladle furnace is completed, the sulfur content increases in waste refining slag which has higher basicity and a certain sulfur capacity, This is not conducive to the recycling of waste LF refining slag resources [4].

reduced and $60 \%$ of phosphorus enters molten iron and $40 \%$ was gasified. Li G. Q. [6] carried out high temperature carbothermal reduction dephosphorization of converter steel slag, the results showed that $62.7 \%$ of phosphorus in slag entered into Fe-C alloy and $32.8 \%$ entered into gas phase in $1800^{\circ} \mathrm{C}$, the dephosphorization ratio reached $95.5 \%$. Nagata 
Kazuhiro [7] reduced hot metal pretreatment slag (5.5wt\% $\left(\mathrm{P}_{2} \mathrm{O}_{5}\right)$ in slag) with carbon powder at $1665^{\circ} \mathrm{C}$, in which phosphorus volatilized $20 \%$, absorbed $70 \%$ by iron and remained $10 \%$ in slag. Wang S. H et al. [8] studied the that gasification dephosphorization of converter slag with reduction by Silicon, the results showed that the temperature had the greatest influence on the dephosphorization, and the greatest gasification dephosphorization rate of slag could reach $81.23 \%$ as shown in Figure 1. However, these treatment methods needed a long time and treatment temperature is too high, so the slag must be reheated in practical application.

\subsection{Research on Removal of Sulfur from Waste Refining Slag}

At home and abroad, there are two main methods to remove sulfur from refining slag, oxidation method and hydrothermal method. Gu Jiemei et al.[9] studied the roasting desulfurization of waste LF refining slag. Because sulfur mainly existed in the slag in the form of $\mathrm{CaS}$ and $11 \mathrm{CaO}-7 \mathrm{~A}_{2} \mathrm{O}_{3}-\mathrm{CaS}$ solid solution, the oxidation reaction of sulfur was hindered and the desulfurization effect was poor. Hiraki T.[10] introduced $\mathrm{Ar}+21 \% \mathrm{O}_{2}$ mixed gas into waste refining slag at $1100^{\circ} \mathrm{C}$ for oxidative roasting desulfurization and the sulfur removal rate was about $95 \%$. Wang Deyong [11] blew $\mathrm{O}_{2}$ into waste refining slag, or Lin $\mathrm{Lu}$ [12] and Zhou Jian'an [13] used $\mathrm{Fe}_{2} \mathrm{O}_{3}$ or iron ore to mix with waste refining slag, The content of sulfur in the roasted slag decreased obviously, and the desulfurization rate was $98.1 \%$ [13], and the desulfurized slag could be used as flux for converter steelmaking or hot metal pretreatment. Taking advantage of the fact that $\mathrm{CaS}$ was easy to react with water, the research on hydrothermal leaching of sulfur from waste refining slag was carried out [14]. Under the condition of $150^{\circ} \mathrm{C}$, the removal rate of sulfur could reach $46.5 \%$ [15]. Sulfur entered into leaching solution in the form of $\mathrm{S}^{2-}$, and combined with $\mathrm{H}^{+}$ released by hydrolysis to form HS first and then $\mathrm{H}_{2} \mathrm{~S}$, so as to achieve the purpose of leaching and removing sulfur waste from slag. The regeneration desulfurization reaction of spent slag was carried out under subcritical conditions [16]. The reaction was a multiphase reaction between solid phase and fluid phase, which could significantly improve the reaction

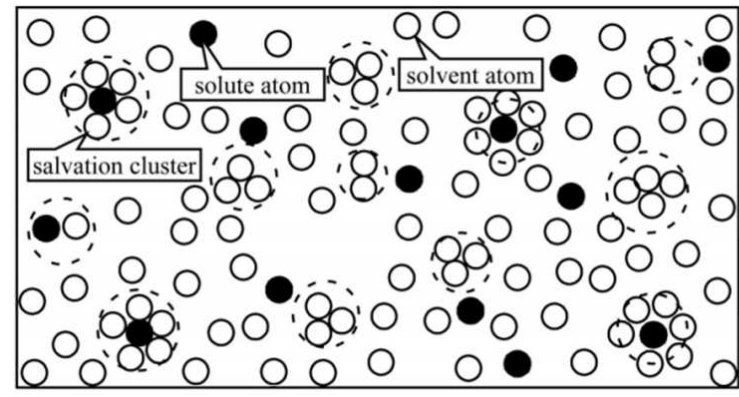

(Before PEF treatment) rate. But for the oxidation process it was difficult to be realized due to the limitation of production space, and for the hydrothermal process the sulfur existed in the form of $\mathrm{Ca}_{12} \mathrm{Al}_{14} \mathrm{O}_{32} \mathrm{~S}$ solid solution in slag, which led to the inhibition of desulfurization reaction [4].

The above phosphorous or sulfur removal treatment can change the chemical activity of the main components in the slag and affected its recycling efficiency. The molten slag system was composed of phosphorus containing converter slag or sulfur containing refining slag and a certain amount of liquid steel (iron). The electric field is used to strengthen the direct treatment of the melt, so as to promote the directional migration of impurity element phosphorus (or sulfur) to liquid steel (iron), so as to realize the efficient separation of slag and impurity elements, and improve the comprehensive utilization efficiency of metallurgical slag.

\section{Research on Metallurgical Process Strengthened by External Electric Field}

The electric field treatment began in the 1960s. Adding continuous DC current to the solidification process of liquid metal can significantly refine the grain structure. Applying pulse current treatment can control the solidification structure and properties of the material. The literature reports focused on the effects of the two treatments on the physical and chemical properties of the melt and the mass transfer reaction of components.

\subsection{The Structure and Properties of Metallurgical Melt Change Due to External Electric Field}

Electric field treatment of metallurgical melts originated from the study of direct current electric field (DEF) on metal solidification, the main purpose was to study the effect of electric field on solidification structure, grain refinement and material properties, including $\mathrm{Sn}-\mathrm{Pb}$ alloy [17-18], Al-based alloy [19-20], high temperature Ni-based alloy [21] and steel melt [22-24], and carbon reduction of iron ore in different atmospheres promoted by electric current [25].

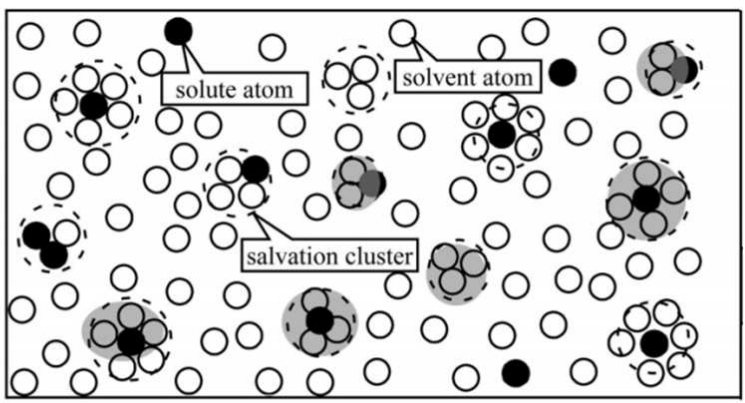

(After PEF treatment)

Figure 2. Alloy melt structure transformation under PEF treatment [26].

The study on the physical properties of slag-metal system in electric field showed that the partition coefficient of copper increased obviously, the activity of solute $\mathrm{Cu}$ decreased from
0.1143 to 0.0385 significantly after PEF treatment of $\mathrm{Al}-\mathrm{Cu}$ melt and $\mathrm{Pb}-\mathrm{Cu}$ melt as shown in Figure 2. [26], the melt structure changed and caused the changes of activity and 
equilibrium partition coefficient [27]; the application of electric field could also improve the wettability between $\mathrm{Cu} / \mathrm{W}$ and $\mathrm{Cu}(\mathrm{Fe}) / \mathrm{W}[28-29]$, to increase the solid solubility of copper in Al [30]. In addition it reduced the valence electron density and internal energy of $\mathrm{Al}-\mathrm{Cu}$ alloy, decreased the increasing of energy caused by $\mathrm{Cu}$ and other solutes entering into the matrix, and promoted the solid solution ability of solute $\mathrm{Cu}$ atom in $\mathrm{Al}$ matrix [31].

Under the condition of electric field, the viscosity of mold flux with lower alkalinity changed with the increase of voltage, which was smaller than that of mold flux with higher alkalinity. The melting point of mold flux decreased after the application of electric field, and the lower the basicity, the more obvious the melting point decreased [32], and the more obvious the viscosity change effect of $\mathrm{CaO}-\mathrm{SiO}_{2}-\mathrm{Al}_{2} \mathrm{O}_{3}$ slag system [33]. The effect of electric field could improve the crystallization rate of mold flux, and the precipitation amount of two main phases (They are respectively cuspidate $\mathrm{Ca}_{4} \mathrm{Si}_{2} \mathrm{O}_{7} \mathrm{~F}_{2}$ and melilite $\left.\mathrm{Ca}_{2} \mathrm{Al}\left[\mathrm{AlSiO}_{7}\right]\right)$ in mold flux increased obviously with the increase of DC voltage, and decreased with the increase of alternating voltage [34]. The changes of physical and chemical properties of steel-slag reaction system in the process of electric field strengthening needed to be further clarified.

\subsection{External Electric Field Enhances Mass Transfer Reaction in Metallurgical Process}

Due to the electrochemical capillary activity and migration of

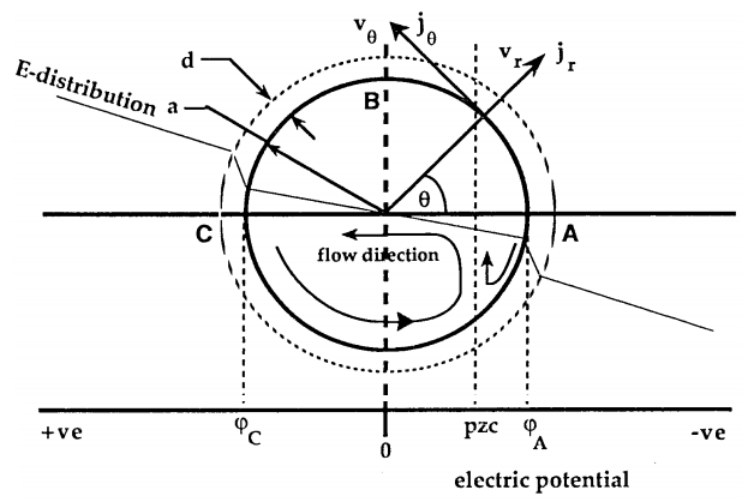

copper droplets in the copper bearing metallurgical slag treated by electric field, there were almost no metal copper droplets in the positive area, and a large amount of metal copper tended to migrate to the cathode area, with the highest enrichment rate of more than 80\% [35-37], it represented the electric field E passed through droplet as well as the electrocapillary motion within droplet in Figure 3. When direct current was applied to copper-containing $(\mathrm{FeO})$-rich slag, the potential gradient at the slag-metal interface increased with the increase of applied voltage, and the enrichment rate of cathode copper increased significantly [38]. Direct current dilution had an obvious effect on promoting the reduction of copper in copper-containing slag, accelerating the separation of copper matte and slag [39], the radius of copper drop in slag also increased with the increase of treatment time [40].

The research on oxygen transfer between molten iron and molten copper showed that the final carbon content of molten iron was much lower than that without electronic conductor when the electronic conductor was penetrated the $\mathrm{Fe}-\mathrm{C}$ melt and molten slag system, and the reaction rate was $2 \sim 3$ times [41] or even 3 4 times [42] of the latter as showed in Figure 4. By establishing the electrochemical model of oxygen ion migration in slag phase for slag-steel reaction [43], it was proposed that the electric field applied in ladle furnace was pollution-free smelting method [44-45], applying DC pulse electric field to control the transfer direction and speed of oxygen atoms from molten steel or molten metal and slag system, it could remove dissolved oxygen from molten copper to $10 \times 10^{-6}[46]$.

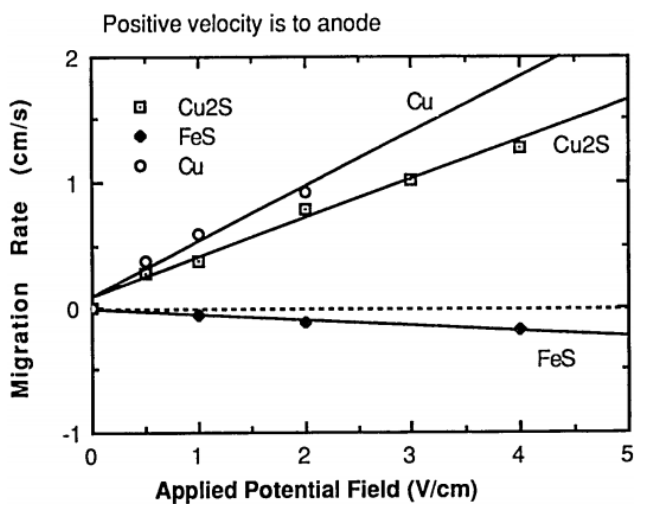

Figure 3. Droplet in solution under the influence of an electric field E and Migration rates of copper, copper sulphide, and iron sulphide droplets [37].

According to the existing research on oxygen transfer and interlayer reaction between slag and metal, the electric field could promote the mass transfer and reaction ability, which provided a theoretical support for these researches on the slag-metal reaction treated by electric field and the migration

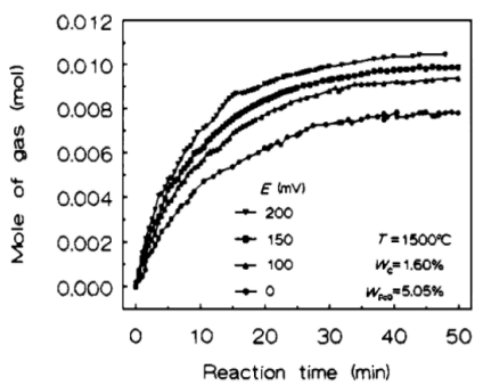

Figure 4. Effect of electrodes number and applied voltage on reaction [42].

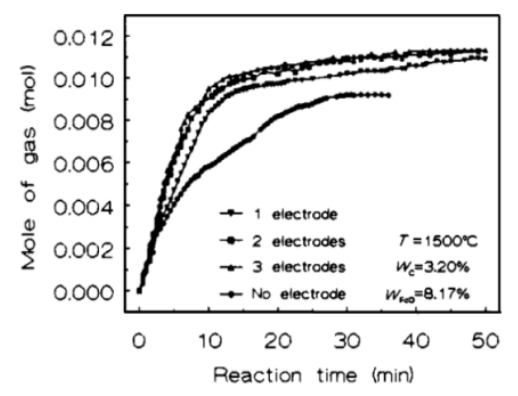

mechanism of impurity elements and inclusions, and it could reveal the electrochemical reaction characteristics, the migration and separation law of impurity elements for slag-metal reaction system in metallurgical process. 


\subsection{Enhanced Element Migration by Electric Field}

The above results showed that the physicochemical properties of molten metal and slag were changed in different degrees under the action of electric field, and the migration ability of components in different melts was also different. The change of these properties would inevitably affect the reaction between slag and metal. Posch W.[47] studied the occurrence form of sulfur in slag, when there were enough sulfur ions in slag, $(\mathrm{CaS})$ would be precipitated in the form of $\mathrm{Ca}^{2+}+\mathrm{S}^{2-}=(\mathrm{CaS})$, which was of great significance for electric field strengthening slag desulfurization.

The effect of pulsed electric field (PEF) on the migration and distribution of elements in iron-based melt was studied. The results showed that the effect of PEF on Fe-j and Fe-C-j was obvious $(j=S i, M n, P, S)$ solute elements have different migration effects, and the distribution characteristics of different components in the positive and negative electrodes of the electric field were different [48-50]. For example, carbon and phosphorus showed a similar migration laws, the segregation degree of phosphorus and carbon decreased with the increase of voltage [51], while sulfur migrated from the positive electrode to the negative electrode, and carbon and sulfur had opposite migration laws [52].

The electric field could promote the migration of sulfur between molten steel and molten steel, and the reverse migration of phosphorus from molten steel to molten slag under the action of DC electric field [53]. This reverse migration phenomenon of phosphorus also provided a new idea for phosphorus removal of high content steel slag. Under the action of electric field, the phosphorus (or sulfur) capacity of molten slag also changed, which was a non-equilibrium phosphorus (or sulfur) capacity different from conventional thermodynamic properties. The non-equilibrium phosphorus capacity under electric field was lower than conventional equilibrium phosphorus capacity, which improved the phosphorus removal efficiency of phosphorus-containing steel slag.

\subsection{Prospect of Future Work}

In order to improve the efficiency of slag-metal reaction in metallurgical process, it is necessary to study the effect of electric field on metal melt and slag and the electrochemical mechanism of slag-metal reaction, and carry out in-depth research on the migration and control of impurity elements phosphorus (sulfur) between slag and metal in the process of electric field strengthening metallurgical reaction. Aiming at the influence of electric field treatment on slag metal reaction, the effects of different electric fields, such as pulse electric field and DC electric field, different electrode types, such as steel electrode, molybdenum electrode and graphite electrode, different electrode application methods, such as positive direction application and reverse direction application, as well as different voltage and treatment time, on phosphorus removal from steel slag and sulfur removal from refining waste slag need to be studied.

According to the research being carried out by the author, it is shown that the reverse applied DC electric field can obtain good phosphorus removal effect, and the phosphorus removal rate can exceed $95 \%$. The efficient separation of impurity elements by the properties of metal melt and slag, it can be extended to slag-metal reaction system, such as hot metal pretreatment slag, copper slag and so on, to improve the dephosphorization or desulfurization efficiency of metallurgical process reaction.

\section{Conclusions}

In order to improve the recycling efficiency of steel slag and waste refining slag, it is necessary to remove phosphorus from phosphorus-containing steel slag and sulfur from sulfur-containing waste refining slag.

(1) Deepening the research on the properties of slag to promote the slag-metal reaction and strengthen the metallurgical process was an important means to improve impurity removal from molten slag.

(2) The removal methods of phosphorus from steel slag included carbon/silicon reduction and gasification dephosphorization, but the treatment temperature was relatively high; the sulfur removal methods of phosphorus from waste refining slag mainly included oxidation method and hydrothermal method, and the sulfur removal effect of oxidation method was better than hydrothermal method. The chemical activity of the main components in molten slag treated by the above methods affected its recycling efficiency.

(3) The applied electric field changed the structure and physicochemical properties of metallurgical melt, and the activity and migration ability of components, which could promote the migration of impurity elements and improve the efficiency of slag-metal reaction in metallurgical process, the electric field treatment improved the phosphorus removal efficiency of phosphorus-containing steel slag and sulfur removal efficiency of sulfur-containing waste refining slag.

\section{Acknowledgements}

Thanks to the National Natural Science Foundation of China-Steel Joint Research Fund for funding this research project (Grant No. U1760117 and No. U1760202).

\section{References}

[1] Wen Liangying, Chen Dengfu, Bai Chenguang, Dong Lingyan, Xu Yuan, Qiu Guibao, Zhou Yuanhua, Liao Ming, Chen Hao, A Study of Premelted refining slag for ladle furnace (LF) [J], Special Steel, 2003, 24 (2), pp. 13-15. (in Chinese).

[2] Kajioka Hiromiyuki, Translated by Li Hong, Ladle Refining [M], Beijing: Metallurgical Industry Press, 2002. (in Chinese).

[3] Lu Xionggang, Electrochemical Control of Slag-metal Reaction [M], Beijing: Higher Education Press, 2001. (in Chinese). 
[4] Liu Hanghang, Research on Theory and Method of LF Refining Slag Desulfurization [J], Shandong metallurgy, 2014, 36 (2), pp. 46-49. (in Chinese).

[5] Yoshio Shimotsuke, Akira Yanagiida, Kenzo Yamada, et al. Treatment method of Molten Steel Slag [P], Japanese Patent: Special Edition 51-121030, 1975.

[6] Li Guangqiang, Zhang Feng, Zhang Li, Sui Zhitong, Recycle of converter slag by high temperature carbon thermal reduction [J]. Journal of Materials And Metallurgy, 2003, 29 (3), pp. 167-172. (in Chinese).

[7] Nagata Kazuhiro. Vaporization dephosphorization of slag with Calcium sulphate [A], Reduction and Resource Utilization of Steel Slag [C]. Japan Iron and Steel Association, 1997, pp. 49-56.

[8] Wang Shuhuan, Wu Yanqing, Liu Xinsheng, Experimental Study on Gasification Dephosphorization of Converter Slag With Reduction by Silicon [J]. Iron and steel, 2008, 43 (2), pp. 31-34. (in Chinese).

[9] $\mathrm{Gu}$ Jiemei. Research on Desulfurization of metallurgical sulfur-containing slag by oxidative roasting [D]. Shenyang: Northeast University, 2011. (in Chinese).

[10] Hiraki T, Kobayashi J, Urushibata S, Kazuyo Matsubae \& Tetsuya Nagasaka. Removal of sulfur from $\mathrm{CaF}_{2}$ containing desulfurization slag exhausted from secondary steelmaking process by oxidation [J]. Metallurgical and Materials Transactions B, 2012, 43 (4), pp. 703-709.

[11] Wang Deyong; Wu Yonglai; Jiang Maofa; Liu Chengjun; Yang Zhenghong; Huang Zhenqiu, the utilization method of waste refining slag containing sulfur for refining slag, Chinese patent, CN200910264646. X, 2009.

[12] Lin Lu, Bao Yanping, Wang Min, Wu Qifan, Zhao Lihua, Li Xiang, $\mathrm{Gu}$ Chao, A process for desulfurization and metallurgical internal recycling of LF refining slag $[\mathrm{P}]$, Chinese patent, CN201410360962.8, 2014.

[13] Zhou Jian'an, Li Shu, Wang Bao, A desulfurization treatment method of metallurgical waste refining slag, Chinese patent, CN201910699218.3, 2019.

[14] He Huanyu, Zeng Zhaozhi, Liu Jigang, Xu Bin, Cheng Rijin. Mechanism of sulfur removal from LF slag by hydrothermal leaching $[\mathrm{J}]$. Journal of Wuhan University of science and technology, 2010, 33 (1), pp. 6-9. (in Chinese).

[15] He Huanyu, Wang Jieqi, Chen Zhenhong, Song Zeyu, Physicochemical properties of LF refining spent slag after hydrothermal leaching, Journal of Wuhan University of Science and Technology, 2016, 39 (1), pp. 7-11.

[16] He Huanyu, Ni Hongwei, Liu Jigang, Xia Xiaoliang, Wu Danjiang. Effect of subcritical water on spent slag regeneration desulfurization [J]. Journal of process engineering, 2009, 9 (1): pp. 230-232. (in Chinese).

[17] Asai S, Effect of electric and magnetic force on solidified structure [J], Trans ISIJ, 1978, vol. 18, pp. 754-760.

[18] Misra A K, A novel Solidification technique of metals and alloys: under the influence of applied potential [J], Metall Trans. A, 1985, vol. 16A, pp. 1354-1355.

[19] Crossley F A, Fisher R D, Metcalfe A G. Viscous shear as an agent for grain refinement in cast metal $[\mathrm{J}]$, Trans Metall Soc
AIME, 1961, vol. 221, pp. 419-420.

[20] Zhou Quan, Yang Yuansheng, Grain refinement of aluminum by low-voltage electric pulse discharge [J], Hot Working Technology, 2006, 35 (1), pp. 16-18. (in Chinese).

[21] Li Wanfeng, Yang Yuansheng, Yu Li, Zhang Yun, Hu Zhuanglin, Effect of DC electric field on the microstructure of nickel base superalloy $\mathrm{K} 417 \mathrm{~g}[\mathrm{~J}]$, Journal of Materials Engineering, 2001, (9), pp. 7-9. (in Chinese).

[22] Wang Jianzhong, Cang Daqiang, pulse inoculation of liquid metal [P], Chinese Patent: CN98100543.8, 1998.

[23] Tang Yong, Wang Jianzhong, Cang Daqiang, Effect of Pulse Electric Discharging on Solidification Structure of High Carbon Steel [J], Journal of iron and steel research, 1999, 11 (4), pp. 44-47. (in Chinese).

[24] Tang Yong, Wang Jianzhong, Cang Daqiang, Wang Jingsong, Zhao Yuxiang, Improvement of T8 steel solidification structure by electricpulse treatment [J], Journal of University of science and technology Beijing, 2000, 22 (4), pp. 307-311. (in Chinese).

[25] A. Rousu, O. Mattila and P. Tanskanen, A Labratory Investigation of the Influence of Electric Current on the Burden Reactions in A Submerged Arc Furnace [C], The 12th Int. Ferroalloys Congress, Helsinki, Finland, 2010, pp. 303-310.

[26] Zhang Zhenbin, Wang Jianzhong, Qi Jingang, Wang Bing, he Lijia, Cang Daqiang, Effect of pulsed electric field on activity of $\mathrm{Al}-10 \% \mathrm{Cu}$ melt $[\mathrm{J}]$, Journal of materials science and engineering, 2008, 26 (4), pp. 647-650. (in Chinese).

[27] Wang Jingsong, Xue Qingguo, Shi Xiangdong, fan Fangguo, $\mathrm{Xu}$ Jianguo, Cang Daqiang, effect of electric pulse treatment on dendrite morphology in solidification structure of $\mathrm{Sn}-15 \% \mathrm{~Pb}$ alloy [J], Journal of Beijing University of science and technology, 2005, 27 (2), pp. 193-196. (in Chinese).

[28] Li Dasheng, Fan Zhikang, Effects of Chromium and Electrical Field on Wettability between Copper and Tungsten [J], Rare Metal Materials and Engineering, 2007, 36 (6), pp. 1008-1011. (in Chinese).

[29] Sun Deguo, Investigation of electrical field and elements (Fe and $\mathrm{Co}$ ) on the wettability of copper and tungsten [D], Master's thesis of Xi'an Jiaotong University, 2008. (in Chinese).

[30] Ban Chunyan, Fundamental study on solidification of Al alloy under electromagnetic fields [D], Doctoral Dissertation of Northeast University, 2002. (in Chinese).

[31] Liu Bing, Chen Zheng, Influence of electric field and of Al-Li alloy containing Cerium and its electric mechanism [J], Journal of Chinese Rare Earth Society, 2001, 19 (1), pp. 58-61. (in Chinese).

[32] Wei Zhiwen, Basic research on properties of molten mold flux under electric field [D], Master's thesis of Chongqing University, 2010. (in Chinese).

[33] Kensuke OKAZAWA, Masahiro YAMANE and Yuka FUKUDA, Viscosity Change of Molten Oxides by Electric Current Imposition [J], Tetsu to Hagane, 2003, 86 (6), pp. 629-636.

[34] Wang Yu, Wang Yanhui, Zeng Xiaolan, Liang Xiaoping, Wei Zhiwen, Crystallization properties of mould fluxes under electric field [J], Journal of Iron and Steel Research, 2012, 24 (5), pp. 10-13. (in Chinese). 
[35] Fang Liwu, Hong Xin, Li Changrong, Chen Hua, A study on setting behavior of copper drops in copper slag under electric field [J], Shanghai Metals, 2006, 28 (6), pp. 28-31. (in Chinese).

[36] A. Warozok, T. A. Utigtud. Setting of copper drops in molten slags [J], Metall. and Mat. B: Process Metall. Mater. Pro. Sci.. 1995, 26 (6), pp. 1165-1173.

[37] R. T. C. Choo, J. M. Toguri, The electrodynamic behavior of metal and metal sulphide droplets in slags [J], Can. Metal Q., 1992, 31 (2), pp. 113-117.

[38] Li Qiuju, Chen Peng, Lin Jiangduo, Mao Jiajun, Behavior of $\mathrm{Cu}$ droplets migration in FeO-rich molten slag under electric field [J], Journal of Materials and Metallurgy, 2010, 9 (1), pp. 28-30. (in Chinese).

[39] Bai Houshan, Jin Zhenn, Lang Xiaozhen, He Jiaqi, DC dilution of copper smelting slag [C], Proceedings of 2002 National Symposium on copper smelting production technology and product application, China Nonferrous Metals Society, 2002, pp. 40-45. (in Chinese).

[40] Li Changrong, Jiang Mingli, Micro-examination of Copper Droplet Electro-capillary Migration in the Copper Smelting Slag [J], Modern Mining, 2011, (2), pp. 44-46. (in Chinese).

[41] Lu Xionggang, Li Fusang, Hu Xiaojun, Li Lifen, Zhou Guozhi, Electrochemical mechanism of reaction between $\mathrm{Fe}-\mathrm{C}$ melt and slag [J], Engineering Chemistry \& Metallurgy, 1999, 20 (3), pp. 278-282. (in Chinese).

[42] Lu XiongGang, Li FuShen, Li LiFen, Zhou GuoZhi, Effect of applied voltage and electrode on reaction between melt and slags [J], Engineering Chemistry \& Metallurgy, 1999, 20 (04), pp. 402-404. (in Chinese).

[43] Lu xionggang, Study on electrochemical mechanism of decarbonization of steel slag [D], Doctoral Dissertation of Beijing University of science and technology, 1998. (in Chinese).

[44] Zhang Jieyu, Xu Jifang, Wang Bo, LU Xionggang, Zhou Guozhi, Li Qian, LI Jianchao, Chai Na, deoxidation refining method and device without pollution by external electric field in ladle furnace [P], Chinese patent, patent No. 200810034135, 2008 .
[45] Li Jianchao, Zhang Jieyu, Lu Xionggang, Zhou Guozhi, Zhou Weiguang, Liang Xinteng, Unpolluted Deoxidization of Molten Steel with Applied DC Voltage between Metal and Slag [J], The Chinese Journal of Process Engineering, 2006, 6 (S1), pp. 30-34. (in Chinese).

[46] Lu xionggang, Liang Xiaowei, Yuan Wei, sun Mingshan, Ding Weizhong, Zhou Guozhi, study on unpollution deoxidation method with applied voltage between metal and slag [J], Acta metallurgica Sinica, 2005, 41 (2), pp. 113-117. (in Chinese).

[47] Posch W, Preblinger H, Mary M, et al. Sulphur Bonding in Solidified Ladle Slags [C], VII International Conference on Molten Slags Fluxes and Slats. The South Afrian Institute of Mining and Metallurgy, 2004, pp. 249-254.

[48] Wang Haichuan, Zhang Wangsheng, Liao Zhiyou, min Changiie, Wang Shijun, Dong Yuanchi, Effect of pulse electric field on the solidification microstructure and element distribution of carbon steel [J], Journal of University of science and technology Beijing, 2007, 39 (8), pp. 793-797. (in Chinese).

[49] Wang Haichuan, Hong Peng, Liao Zhiyou, Li Xin, Li Jie, Wang Gui, Wang Shijun, and Matthew S. Dargusch, Effect of Pulsed Current on the Microstructure and Distribution of $\mathrm{C}$ and $\mathrm{Mn}$ in an Fe-0.5C-1.5Mn Alloy [J], Adv. Mat. Res., 2011, vol. 146-147, pp. 1612-1616.

[50] Liao Zhiyou, Wang Haichuan, Hong Peng, Li Xin, Li Jie, Wang Shijun, Wang Gui, and Matthew S. Dargusch. Effect of Pulsed Electric Field on the Distribution and Migration of P, S, and Si Elements of Fe-based Alloys [J], Adv. Mat. Res., 2011, vol. 194-196, pp. 371-374.

[51] Hong Peng, Wang Haichuan, Li Xin, Li Jie, Liao Zhiyou, Qian Zhangxiu, Effect of pulsed electric field on solidification process of Fe-C-P system alloy [J], The Chinese Journal of Process Engineering, 2011, 11 (1), pp. 28-33. (in Chinese).

[52] Liao Zhiyou, Wang Haichuan, Peng Hong, Xin LI, Shijun Wang, Jie Li. Research on Effect of Pulse Electric Field on Solidification Process of Fe-C-S Alloy Melt [J], Adv. Mat. Res., 2011, vol. 284-286, pp. 1137-1142.

[53] Chen Kequan, effect of pulsed electric field on migration characteristics of impurities and alloying elements between slag and metal [D], Master's thesis of Anhui University of Technology, 2013. (in Chinese). 